\title{
Theme and Thematic Progression in Students' Recount Texts: A Systemic Functional Linguistic Perspective
}

\author{
Rispa Mustika*, Naufal Elhaddid Nurdin, Rahma Sakina
}

\author{
Department of English Education, Ma'soem University, Indonesia \\ ${ }^{*}$ Corresponding author. Email: rispamustika21@gmail.com
}

\begin{abstract}
This research paper entitled Theme and Thematic Progression in Students' Recount Texts attempted to investigate how the students organize their ideas in their recount texts, seen from the Theme and Thematic Progression and to figure out the implication of Theme and Thematic Progression used by students for the flow of texts. This research was conducted in a private senior high school in Bandung. The research employed a qualitative design, embracing characteristic of a case study. The data were nine students' Recount texts from three different levels of achievement including low, middle, and high achievers. The findings showed that seen from types of Theme, there were three types of Themes employed by students in their recount texts, namely the topical, textual, and interpersonal Themes in which the topical Theme was the most frequent Theme occurred in the text. In terms of Thematic Progression, there were two dominant patterns used by the students to organize their ideas in their recount Text, including the Theme reiteration and the zig-zag patterns. Themes and Thematic Progression used by the students had the implication for the flow of texts. Furthermore, the use of the cohesion devices (e.g. ellipsis, reference, and conjunction) made the flow of the text much clearer. It was recommended for the teacher to apply Theme and Thematic Progression as the tools to improve students' writing skills and further research to analyze Theme and Thematic Progression on different genre or even spoken texts with different focus.
\end{abstract}

Keywords: cohesion of text, recount text, systemic functional linguistics, theme, thematic progression

\section{INTRODUCTION}

One of the important skills that students must master is writing skill. As stated by Harmer (2007) [1], in the English teaching syllabus (curriculum), writing has always been one part of it. Nevertheless, most of students regard that writing is difficult, especially in organizing their ideas into the written language and maintaining the coherence of the text [2]. Research on ESL/ EFL students' writing found that students are more concerned about the word and sentence levels than the whole discourse level, which is textual coherence [3]. As a matter of fact, grammar is not the only aspect should be considered to make the text coherent and makes sense. To make a good text, several aspects should be accounted including the Theme of clause and Thematic Progression.

Based on Systemic Functional Linguistics (SFL) perspective, Theme refers to an element of clause that serves as a starting point for the message that is what the clause will talk about [4]. This usually consists of information that has been previously mentioned in the text or is familiar from the context. Themes are identified by order, that is, elements appear first in the clause. The rest part of the clause in which the Theme is developed is called Rheme. Because the clauses usually start with familiar information and end with unfamiliar information, Rheme usually contains new information.

Theme is classified into three basic types of Theme covering topical, interpersonal, and textual Themes [5]. Based on its markedness, Theme can be marked and unmarked. The Theme can also be single or multiple. The first type of theme is topical theme, which is also known as an ideational theme. This is the first element in the clause which gives the meaning of representation in relation to the Transitivity function: participant, state, or process. The topical theme is considered the one that all clauses have, whereas the other two themes may or may not appear in the clause. The use of topical themes in the text shows that the writer can convey what the text is and show where the information comes from and where it goes [6].

In addition, topical Theme may appear with other two Themes: Interpersonal and Textual Themes, and this is called as Multiple Themes [7]-[8]. The interpersonal 
Theme functions as interpersonal elements preceding the topical Theme. Such elements functioning as the interpersonal themes are unfused Finite, Mood Adjunct, Comment Adjunct, and Vocative [9]. The unfused Finite is usually realized by an auxiliary verb which indicates that a response is required [10]. Mood Adjuncts are related to the meaning constructed by the mood system such as modality, temporality, and intensity. Comment Adjuncts show the attitude of speaker to the whole clause or to the particular speech function. Vocatives are usually in the form of names or nicknames used to address someone who appears before a Topical Theme.

The last kind of theme is textual Theme that usually appears at the start of a clause and precedes interpersonal themes. It links the clause with its context to make it cohesive [9]. The two main kinds of textual elements that can be used as themes are Continuity Adjunct and Conjunctive Adjunct. Continuity Adjuncts are words used in spoken dialogue to show that the speaker's contribution is related to what the previous speaker said on the previous turn. Such continuity items are oh, well, yes, and no. Conjunctive Addition refers to elements that serve to link sentences together that appear before the first topic theme in the clause. The use of Textual Themes is useful for developing logical relationships between stages in a text and this shows the success of the author in shaping and organizing the text [6].

In addition to three types of Theme elaborated before, Theme is also categorized into Marked and Unmarked Theme. A topical Theme functioning as subject of the clause is called Unmarked Topical Theme. The Unmarked Theme can be in form of pronoun (e.g. I, you, we, he, she, it, they), nominal group complex (e.g. George and Rose), and embedded clause (e.g. What George and Rose do). In contrast, a Theme that is something other than subject refers to Marked Theme. When the writers use the marked Theme, they "signal that all things are not equal, that something in the text requires a typical meaning to be made". This means that Marked Theme is used when the writer want to shift to the new element in the text and it is a way to specify the information stated in the clause for further interpretation [11]. The most common Marked Themes are in form of adverbial group (e.g. today, suddenly, somewhat distractedly) or prepositional phrase (e.g. at night, in the corner, without much hope) which function as Adjunct in the clause, and Complement of the clause (e.g. His crown).

In relation to the use of Marked and Unmarked Theme, the developing writers like students who has limited resources may more focus on the unmarked language patterns: that is, on the expected way of meaning in the particular clause. In other word, the students tend to start their message in the common way for the interpretation of their texts development; that is on subject of the clause [12].

Apart from the Theme of clause, there are also higher level Themes which are called hyper-Theme and macroTheme. The hyper-Theme refers to preliminary sentence or a group of sentences which is formed to predict the particular pattern of interaction among strings, chains and
Theme selection in following sentence [13]. Meanwhile, the macro-Theme is defined as a sentence or group of sentences (possibly a paragraph) which predicts a set of hyper-Theme. The use of higher-level Themes in texts leads the more coherent and cohesive texts which are developed smoothly not only locally, but also globally - a feature which was not present in texts produced prior to the teacher's intervention

Thematic Progression is the exchange of information between Theme and Rheme pairings in a text [14]. It can be used as a structural device to measure the cohesion of text [15]. As stated by Downing (2001), the organization of information in texts is determined by the progression in the ordering of utterance Themes and their Rhemes, also called Thematic Progression [16]. According to Halliday (1994) [15], there are three main patterns of thematic progression; Theme reiteration pattern, zig-zag pattern and multiple-Theme pattern.

Theme reiteration pattern is a Thematic pattern "where the same element occur regularly as Theme". This pattern is beneficial to make the text has a clear focus since the common Theme is shared by all clauses and this Theme equates with given. It can be seen from the Theme which has identical wordings, synonymous expression, paraphrase, or semantic interfere with the previous Theme in the clause.

Zig-zag pattern offers a new information in order to attain the cohesion in the text and this gives the text "a sense of cumulative development", which may not present in the Theme reiteration pattern .This pattern is necessary to make logical relation and elaboration in the text [17]. It also signifies that the text more written-like. Split Rheme Progression (SRP) pattern appears when some elements in Rheme of the first clause are picked up and then made as a Theme of the following clause. It can be identified as the multiple-Theme pattern since the Theme of one clause introduces a number of different pieces of information, each of which is then picked up and made Theme in subsequent clauses.

Some SF theorists agree that generic choice is said to be a condition of the context of culture [13]. A genre is defined as a staged purposive activity undertaken to accomplish some goals. Genres have their particular character because of the context of culture in which they are found [9]. The characteristics include social function, generic structure, and significant linguistic features. There are many genres of text learned by Indonesian students, one of which is Recount Text. Recount is a text that retells past events intending to entertain or inform others what happened and when it happened, usually in a sequence [18]. The schematic structure of this text includes orientation, record of events, and re-orientation [19]. In the orientation, the writer provides background of information including who, what, where and when it happened. In second stage, the writer tells the events in a chronological order. At last, the writer gives personal comments or evaluative remarks that interpret throughout the event. The linguistic features of this text are using specific participants, circumstance of time and place, first person, 
additive conjunction, material process, and past tense [20].

Considering the elaboration above, both Theme and Thematic Progression are necessary for the success of students' writing. A number of researches related to Theme and Thematic Progression was conducted by many researchers on ref [21]-[23]. The studies analyzed Theme with various focuses and Thematic Progressions in varied genres including expository, narrative, argumentative, recount text, academic translated texts, and research article abstract. They described and explained how and why certain Thematic Progression exists in the texts.

Nwogu \& Bloor (1991) declared that most English texts generally organize the Theme reiteration and the zig-zag patterns as the most dominant Thematic Progression patterns in organizing the information of text [21]. However, Wang (2007) asserted that there were several main thematic progression patterns which depend on different text types [14]. As evidence, the Theme reiteration pattern are more dominant in narrative-type text while the zig-zag pattern occurred dominantly in argumentative or expository text or kind of the social science articles. Furthermore, Alboghobeish \& Sedghi (2014) reported the frequent use of the Theme reiteration pattern in the research article abstract [24].

Yang et al. (2007) study compared expository essays written by a Chinese and a North American college students and it showed significant differences in the students' degree of control over the textual resources of theme and rheme, thematic progression, and lexical complexity. Explicit teaching of genres and the specific language has proven effective with English language learners, especially who are culturally and linguistically different [25]

Those previous researches investigated thematic progression in various genre of text, including recount text. However, Purba et al., (2018) analyzed thematic progression in recount texts written by junior high school students whereas this research investigates senior high school students' texts with three levels of achievement: low, middle, and high [23]. The purposes of this research are to analyze how the students organize their ideas in their recount text, seen from Theme and Thematic Progression and to find out the implication of the Theme and Thematic Progression used by students for the flow of text.

At the end, the finding of this research is expected to give some theoretical, practical, and professional contributions. Theoretically, this research can enrich the literature on Theme and Thematic Progression analysis on students' texts. Practically, this research can be one of references on how to analyze students' text based on Theme and Thematic Progression. Professionally, this research is useful for the English teachers to evaluate their strategies in teaching recount texts and to support that Theme and Thematic Progression analysis can be one basis text evaluation for students' writing.

\section{RESEARCH METHOD}

To answer the research problems above, this research used a qualitative design that adheres to the characteristics of a case study approach. This approach was considered appropriate because it provided an intensive and holistic description and analysis of one entity [26]. In this research, the focal point was on the recount text written by the tenth grade students in a private senior high school in Bandung. In addition, this research employed text analysis that is another method of qualitative case studies using SFG, which has a powerful analysis tool. SFG was chosen because it is one of the various linguistic approaches that have been developed well in education. This research was conducted at a private senior high school in Bandung. This school was chosen since the researcher had relation with one of teachers there. The participants involved in this research were chosen purposively, namely nine students from grade ten who had learnt the recount genre. It is in line with Malik \& Hamied, (2014) who stated that the sample in the qualitative research is typically purposive [27]. Therefore, those students were expected to be able to write this genre well. They were then divided into three groups: high achievers, middle achievers, and low achievers based on their writing scores provided by the English teacher.

The data of this research were nine students' recount texts from three different levels of achievement, namely low, middle, and high achievers. In collecting the data, several steps were taken. Firstly, the tenth grade students of a senior high school were chosen purposively as the respondents of this research because they had learnt the recount genre. Secondly, the students were asked to write a recount text. Finally, they submitted the text to the teacher to show that the research was carried out in a natural setting.

The data analysis in this research was divided into three steps: identification of Theme types, identification of Thematic Progression pattern, and drawing out the flow of text. The texts submitted by the students were broken down into numbered clauses and identified in terms of the Theme types. The identification of Theme choice aimed at investigating how the students organized their ideas textually in their text. After being analyzed, all the Themes occurred were then calculated for their frequency of occurrence which was presented in a percentage.

After identifying the theme choice of all clauses, the texts were identified in terms of the Thematic Progression pattern. The Thematic Progression pattern analysis in this research was based on the framework proposed in ref [21]. The Thematic Progression patterns were distinguished into four patterns: the Theme reiteration pattern, the zig-zag pattern, the multiple-Theme pattern, and the slipped theme progression pattern. This identification was intended to see how students elaborate and relate the point made to the supporting information in each clause. After being analyzed, all the Thematic Progression occurred were then calculated for their frequency of occurrence which was presented in a percentage. At last, the researcher drew out the flow of 
students' recount texts by interpreting the identified Themes and realization of Thematic Progression.

\section{FINDINGS AND DISCUSSIONS}

The present research aims to analyze how the students organize their ideas in their recount text, seen from Theme and Thematic Progression and to find out the implication of the Theme and Thematic Progression used by students for the flow of text.

In response to the first research question, the findings and discussion are divided into two main parts which are
Themes and Thematic Progression in Students' Recount Text. In terms of types of Theme, the students' text were analyzed based on the framework proposed by Halliday \& Mathiessen (2004) covering topical, interpersonal, and textual Theme [4]. The topical Themes are further categorized as unmarked and marked Theme. The texts analyzed are nine texts from three levels of achievement, that is, low, middle, and high achievement. The summary of types of Themes used by students across the level of achievement can be presented in the Table 1 .

Table 1 The Use of Themes in Students' Recount Text

\begin{tabular}{llllllllll}
\hline \multirow{2}{*}{ Types of Theme } & \multicolumn{2}{c}{ High Achiever } & \multicolumn{2}{c}{ Middludents } & \multicolumn{2}{c}{ Achiever } & \multicolumn{2}{c}{ Low Achiever } & \multicolumn{2}{c}{ Total } \\
& & F & $\%$ & F & $\%$ & F & $\%$ & F & $\%$ \\
\hline \multirow{2}{*}{ Topical } & Marked & 12 & 10.81 & 18 & 23.38 & 7 & 15.22 & 37 & 15.81 \\
& Unmarked & 66 & 59.46 & 39 & 50.65 & 30 & 65.22 & 135 & 57.69 \\
Interpersonal & 1 & 0.90 & 0 & 0 & 0 & 0 & 1 & 0.43 \\
Textual & 32 & 28.83 & 20 & 25.97 & 9 & 19.57 & 61 & 26.07 \\
Total & 111 & 100 & 77 & 100 & 46 & 100 & 234 & 100 \\
\hline
\end{tabular}

From the Table 1, it can be seen that the Topical Themes are the most dominant theme used by students from all achievement levels with the total percentage $73.5 \%$. The Topical Themes were then broken down into the marked Theme $(15.81 \%)$ and the unmarked Theme $(57.69 \%)$. The unmarked Topical Themes frequently used by students in their descriptive texts are pronoun and nominal group complex. Moreover, the unmarked Themes occur in forms of referential items (i.e. it, this, that) and ellipsis. In ellipsis, the subject, and often also the finite verb, is 'understood' from the context. The most frequent use of the Unmarked Theme in the text indicates that students focus on what the text are telling about [11]. In addition, the linguistic features of recount genre that focuses on specific participants increase the likelihood of the use of the unmarked Theme.

In addition to the unmarked Theme, the marked Themes are quite frequently found in the students' text. Based on the table 1, the marked theme is the third frequent Theme used across levels of achievement with $10.81 \%$ in the high achievement, $23.38 \%$ in the middle achievement, and $15.22 \%$ in the low achievement. The marked Themes occurring in students' descriptive text are mostly in form of adverbial group and prepositional phrase which function as Adjunct of the clause. The quiet frequent use of the marked Theme in the text is because the students rather frequently use the linking words associated with time and prepositional phrase related with place. This is in line with the linguistic features of recount genre that is the use of circumstance of time and place.

The second frequent Theme employed in students' recount text is Textual Theme with the total percentage $26.07 \%$. The frequent use of this Theme reflects students' ability to establish the cohesion of text. As stated by Forey (2002) [28], "the Textual Theme is an important means for expressing logical links between the ideational content of the message in a text and thereby helping the reader understand the text".

The interpersonal Themes are the least Theme found in the text with the total percentage $0.43 \%$. This means that students rarely used modulation and modalization in their texts. The rare use of the interpersonal Theme in students' recount text is acceptable since it commonly occurs in the conversation form (such as in interrogative clause, polarity answer, and vocative adjunct) while the conversation is rarely used in the recount text. To conclude, the Topical Themes are the most dominant Themes occurred in students' recount texts of all levels followed by the use of the Textual Themes. Meanwhile, the interpersonal Themes are rarely used in the texts.

The next analysis in this research was the Thematic Progression pattern analysis based on the framework proposed in ref [16], [5].

The result found that two dominant Thematic Progression patterns occurred in students' recount text, namely Theme reiteration and zig-zag patterns while the multiple-theme pattern only used in low percentage. The last type of Thematic Progression pattern, the slipped rheme progression pattern is not found at all in students' text. In fact, this pattern is less frequent in English text rather than in scientific text which has larger corpus. Hence, the slipped rheme progression pattern is not discussed further. The summary of Thematic Progressions patterns used by students across the level of achievement can be presented in the Table 2 . 
Table 2 The Distribution of Thematic Progression Patterns in Students' Recount Text

\begin{tabular}{|c|c|c|c|c|c|c|c|c|c|}
\hline \multirow[t]{2}{*}{ No. } & \multirow[t]{2}{*}{ Thematic Progression } & \multicolumn{6}{|c|}{ Students Level } & & Total \\
\hline & & $\mathrm{F}$ & $\%$ & $\mathrm{~F}$ & $\%$ & $\mathrm{~F}$ & $\%$ & $\mathrm{~F}$ & $\%$ \\
\hline 1. & Theme reiteration Pattern & 37 & 50.68 & 31 & 47.69 & 33 & 84.62 & 101 & 57.06 \\
\hline 2. & Zig-zag Pattern & 32 & 43.84 & 26 & 40 & 6 & 15.38 & 64 & 36.16 \\
\hline 3. & Multiple-Theme Pattern & 4 & 5.48 & 8 & 12.31 & - & 0 & 12 & 6.78 \\
\hline 4. & $\begin{array}{l}\text { Slipped } \\
\text { Progression }\end{array}$ & - & 0 & - & 0 & - & 0 & 0 & 0 \\
\hline Total & & 73 & 100 & 65 & 100 & 39 & 100 & 177 & 100 \\
\hline
\end{tabular}

The Table 2 shows that Theme reiteration patterns are the most frequent patterns realized by students from all achievement levels with the total percentage $57.06 \%$. The dominance of this pattern indicates that students succeeded to keep the focus of text by repeating its thematic element. The second dominant Thematic Progression patterns employed in students' text are the zig-zag patterns with the total percentage $36.16 \%$. This pattern shows that students have been able to make a logical relation and elaboration in their texts [29]. Moreover, it signifies that the texts are more written-like text.

The least Thematic Progression patterns found in students' text are the multiple-theme progression with $6.78 \%$ from the total patterns. The low frequency of this pattern shows that the students have not been able to manage the organization of their texts yet [7]. The analysis of Thematic Progression in the students' texts from each level will be elaborated further. The analysis is broken down based on the generic structure of descriptive text proposed by ref [19].

The first text analyzed is from low achiever's text (Text 9). Based on the table 2, the low achieving students only use two types of thematic progression: Theme reiteration $(84.62 \%)$ and zig-zag patterns $(15.38 \%)$. In terms of generic structure, the text is succeeded employing three stages including orientation, record of events, and reorientation and the analysis of thematic progression is divided based on those stages. The orientation is consisted of two clauses: dependent and independent clauses. Those clauses cannot be regarded into any thematic progression pattern since the theme of the second clause is not derived to any element in the first clause. Nevertheless, in terms of the schematic structure it introduces the character of the story $I$ who have vacation to Jakarta a week ago.

In the record of events, the text tells about the writer's activities during vacation in Jakarta and when arriving in Bandung. The clauses mostly use the topical unmarked theme $I$ and we as their thematic elements and imply the Theme reiteration pattern. The frequent use of these themes and the Theme reiteration pattern show that the text has a clear focus [5], that is about the activities of $I$ and we in the text. In addition to the unmarked Theme, the text uses the marked Theme in form of prepositional phrase related with time and place (e.g. in the morning, at ten o'clock, [in] my house friend (my friend's house)). This is in line with the linguistic features of recount genre that is the use of circumstance of time and place.

The text also employs the textual Themes and, then, and after several times to structurally link a clause with another clause [1]. The zig-zag patterns occur four times in clause nine, eleven, fifteen and sixteen. The use of this pattern indicates that the students have been able to make a logical relation and elaboration in their texts [19].

The re-orientation stage only comprises one clause initiated by the topical unmarked theme it which refers to holiday. This clause cannot be regarded into any thematic progression pattern since it here refers to the whole activities in the text. This shows that the writer fails to develop the clause coherently with the previous clause. To conclude, this low achiever's text only realize the Theme reiteration and the zig-zag patterns in organizing the text. The Theme reiteration patterns appear more frequently than the zig-zag patterns and it also happens in two other low achievers' texts. In overall result, the Theme reiteration patterns occur 33 times while the zig-zag patterns appear 6 times of 39 clauses.

The second text analyzed is taken from middle achiever's text. As seen in the table 2, the middle achieving students utilize three types of thematic progression patterns: Theme reiteration $(47.69 \%)$, zig-zag (40\%), and multipletheme patterns $(12.31 \%)$. In terms of generic structure, the text has all essential stages of a recount text and the analysis of thematic progression is broken down based on the stages. The orientation stage comprises one clause introducing the character of the story as well as the background of time. It is initiated by the unmarked Topical Theme I followed by a Rheme 'was on holiday from Monday to Sunday last week' which becomes the general notion that introduces a number of different pieces 
of information, that is, the writer's activities on those different days.

In the record of events, the writer introduces the activities proposed in the general notion in the first clause. The writer links the clauses by using the marked Themes 'on Monday and Tuesday, on Wednesday, last Tuesday, and on Saturday'. Each clause becomes the hyper-Theme of the paragraph constructing the multiple-theme patterns which indicate that the writer has clearly "planned" method of development in the text [2]. Thus, the writer has elaborated the information of activities during holiday better than the previous writer due to his/ her good control of the textual resources employed to build the text. The writer uses four marked Themes at strategically useful points to shape the ordering of her account of events [32]. The information of activities on those days employs five Theme reiteration and eight zig-zag patterns with the combination of the unmarked theme $I$ and the marked Themes showing adjuncts of place and time such as there, as long as there, and while in the car. In addition, it uses the textual themes because, but, after, after that, and then to link a clause with another clause structurally [1].

In the reorientation stage, the writer uses the unmarked Theme $I$ with the Theme reiteration pattern. The writer tries to show his/ her personal comment to the throughout event told in the text by using the mental process so happy and this is in line with the schematic structure proposed by Anderson \& Anderson (2003) [19]. To conclude, this middle achiever's text has been able to use three thematic progression patterns in organizing the text, namely the Theme reiteration, the zig-zag, and the multiple-theme patterns. The zig-zag patterns appear more frequently than the Theme reiteration and the multiple-theme patterns. However, it is different with the other middle achievers' texts: the text four has the same amount of the Theme reiteration and the zig-zag patterns while the text six has more the Theme reiteration than the zig-zag and the multiple-Theme patterns. In overall result, the Theme reiteration patterns occur 31 times, the zig-zag patterns appear 26 times, and the multiple-theme patterns emerges 8 times of 65 clauses.

The last text analyzed is from high achiever's text. As seen in the table 2, the high achieving students utilize three types of thematic progression patterns: Theme reiteration $(50.68 \%)$, zig-zag $(43.84 \%)$, and multipletheme patterns $(5.48 \%)$. As the previous texts, this text has all essential stages of a recount text. However, it provides more elaboration toward the activities being told than the low and the middle achievers' texts. It can be seen from the number of the clause which is most among the other texts. The analysis of thematic progression is broken down based on its stages.

The orientation of this high achiever's text is established by seven clauses that introduce the character of the story as well as the background of time and place. This stage employs the marked Theme last week, the unmarked Theme I, all, who, it, and the textual Themes but, although, because with five zig-zag patterns and a Theme reiteration pattern.
In the record of events, the writer introduces the activities proposed in the general notion in the previous clause by using the topical Theme it and textual Themes secondly, then, and fourthly to link the next clauses. Each clause becomes the hyper-Theme of the paragraph constructing the multiple-theme patterns which indicate that the writer has clearly "planned" method of development in the text [13]. Similar to the previous text, the writer of this text has managed the information of activities, which cause her tired, better than the low achieving writer. He has good control of the textual resources employed to build the text by using three textual Themes at strategically useful points to shape the ordering [30]. The hyperThemes here are elaborated by sufficient information about the activities that make the writer tired during holiday. The writer employs seven zig-zag and three Theme reiteration patterns with the dominant unmarked Themes (such as it, my aunt, I, the floor, baby's cloth, and people) in all clauses in organizing the information. The dominant use of the unmarked Themes is common for students since developing writers like students usually focus at first on unmarked language patterns: that is, on the expected way of meaning in the particular clause.

The reorientation stage is built by twelve clauses with the realization of nine Theme reiteration and three zig-zag patterns and the dominant use of the unmarked Theme $I$ in all clauses. Here, the writer shows his feeling to the throughout event told in the text by using the mental process very tired. In conclusion, this high achiever's text has been able to use three thematic progression patterns in organizing the text, covering the Theme reiteration, the zig-zag, and the multiple-theme patterns. The zig-zag patterns occur more frequently than the Theme reiteration and the multiple-theme patterns in the text. However, it is different with two other high achievers' texts: the text two has more Theme reiteration than the zig-zag patterns while the text three has more zig-zag than the reiteration patterns. In overall result, the Theme reiteration patterns occur 37 times, the zig-zag patterns appear 32 times, and the multiple-theme patterns emerges 4 times of 73 clauses.

The following explanation attempts to answer the second research question that is the implication of Theme and Thematic Progression on the flow of the texts. There are many ways to investigate the flow of text, one of which is through ithe Thematic pattern. As stated by Downing (2001), the flow of text can be observed through Thematic pattern developed in the text since the text organization is closely connected with discourse coherence [16]. This is also supported by [11] that the most striking contribution of Thematic choice is to the internal cohesion of the text: skillful use of Thematic selection results in a text which appears to 'hang and make sense'. Thus, the Thematic Progression is the essential component in the construction of cohesive and coherent text.

Based on the findings, the Theme reiteration patterns are the most frequent pattern used by the students in their recount texts. In this pattern, the Theme is re-expressed in the subsequent clause so it leads the readers' attention to the topic under discussion. As proposed by Eggins (2004) 
[8], this pattern is a basic way to keep a text focused (i.e. cohesive) and an effective means of creating cohesion. Nevertheless, it tends to be monotonous if it is used in the whole text. Therefore, the writer needs to use the other type of Thematic pattern.

The second frequent patterns occur in the text are the zigzag patterns. In this pattern, a new information is offered in order to attain the cohesion in the text and it gives the text "a sense of cumulative development", which may not present in the Theme reiteration pattern. The use of this pattern also indicates that the students have been able to make a logical relation and elaboration in their texts [19]. The frequent use of the Theme reiteration and the zig-zag patterns in the students' texts is aligned with what Nwogu \& Bloor, (1991) found that most English texts in general organize the Theme reiteration and the zig-zag patterns as the most dominant Thematic Progression.

In addition, the realization of the multiple-theme pattern, though in small numbers, that becomes the hyper-Theme of the paragraph helps to re-orient the reader's expectations for the direction of the unfolding text [11]. It indicates that the writer has a clearly "planned" method of development in the text [2].

The other way to investigate the flow of the text is by examining the cohesion devices: reference, ellipsis, conjunction, and lexical organization. However, the cohesion in this research is focused only on the aspects represented in types of Theme and Thematic Progression patterns. Based on the findings, some unmarked Topical Themes are realized in forms of reference and ellipsis and they occur frequently in the text. This shows the students' ability to refer to the previous items being presented. The conjunction is realized in the textual Themes which often occur in the text with $26.07 \%$. This shows that the students are able to express the logical links between the ideational content of the message in a text and thereby helping the reader understand the text.

To conclude, theme and thematic progression used by students in their recount texts has the implication to the cohesion and cohesive of the text. It helps the readers to comprehend the text easily since the information is developed smoothly.

\section{CONCLUSION}

As mentioned previously, this research is intended to analyze how the students organize their ideas in their recount text, seen from Theme and Thematic Progression and to find out the implication of the Theme and Thematic Progression used by students for the flow of text.

Based on the findings, several conclusions can be drawn from the research. In terms of the realization of Theme, it was found that there are three types of Theme employed by students in their recount text, namely the topical, interpersonal, and textual Themes. Among the three, the topical Theme is the most frequent Theme used by students in organizing the text. The dominant use of this
Theme reveals that students focus on what the texts are telling about. The second frequent Theme occurred in students' recount text is the Textual Theme that shows students' ability to establish the text cohesion. The least Theme found in students' texts is the interpersonal Theme and this means that students rarely use modulation and modalization in their texts.

Regarding to the realization of Thematic Progression patterns, the students have organized their ideas in three ways of Thematic Progression patterns. The two dominant Thematic Progression patterns employed are the Theme reiteration and the zig-zag patterns while the multipleTheme patterns only occur in small number. The frequent use of Theme reiteration pattern indicates students' ability to keep the text focused by restating the Theme in subsequent clauses. The students also shows their ability to make a logical relation and elaboration in their texts by the zig-zag pattern. Furthermore, some of them are able to organize their texts in the beginning clauses and distribute the record of events as hyper-Theme in preceding clause as they apply the multiple-theme pattern.

In terms of the implication of Theme and Thematic Progression used by students on the flow of text, the findings show that the texts produced by the students flow smoothly seen from the high number of the Theme reiteration and the zig-zag patterns employed. Through these patterns, the students keep their recount texts focused and attain the cohesion in the text by providing the cumulative development of information to the text. In addition, by employing the cohesion devices such as ellipsis and reference (that are realized in the unmarked Themes) as well as conjunction (which is realized in the textual Themes), the students improve the clarity and the flow of texts.

\section{REFERENCES}

[1] J. Harmer, The practice of English language teaching, England: Pearson Education Limited, 2007.

[2] E. Emilia, A critical genre based approach to teaching academic writing in a tertiary EFL context in Indonesia, Doctoral dissertation, 2005.

[3] I. Lee, Enhancing ESL students' awareness of coherence-creating mechanisms in writing. TESL Canada Journal, (1998) 36-49. DOI: https:// doi.org/10.18806/tesl.v15i2.700

[4] M. A. Halliday, An introduction to functional grammar, London: Arnold, 2004.

[5] S. Eggins, An Introduction to Systemic Functional Linguistics. London: Printer Publishers, Ltd. 1994.

[6] D. Butt, R. Fahey, S. Feez, S. Spinks, C. Yallop, Using functional grammar: An explorer's guide. New York: Pearson, 2003. 
[7] M. A. K. Halliday, C. M. Matthiessen, An introduction to functional grammar. edward arnold, london. Australian Rev. Appl. Linguist, 10 (2) (1985) 163-181.

[8] S. Eggins, Introduction to systemic functional linguistics. Canada: A\&C Black, 2004.

[9] G. Wignell, L. Gerot, Making Sense of Functional Grammar, Australia: Macquuire University 1994.

[10] E. Emilia, Teaching writing: Developing critical learners. Bandung: Rizqi Press, 2010.

[11] E. A. Thomson, Theme unit analysis: A systemic functional treatment of textual meanings in Japanese. Functions of language, 12 (2) (2005) 151179.

[12] G. Lock, Functional English grammar: An introduction for second language teachers. Cambridge: University Press. 1996.

[13] J. R. Martin, System and structure. London: Pearson: 1992.

[14] L. Wang, Theme and rheme in the thematic organization of text: Implications for teaching academic writing. Asian EFL Journal, 9 (1) (2007) 164-176.

[15] M. A. K. Halliday, An Introduction to Functional Grammar, London: Edward Arnold, 1994.

[16] A. Downing, Thematic progression as a functional resource in analysing texts. Spain: CLAC (Circulo de Lingüistica Aplicada a la Communicacion) 2001.

[17] M. J. Schleppegrell, The language of schooling: A functional linguistics perspective, New York: Routledge. 2004.

[18] B. Derewianka, Exploring How Text Work. Australia: National Primary English Primary Teaching Association, 1995.

[19] M. Alderson and K. Anderson, Text types in English 3. Australia: South Yarra Macmillan Education, 2003.

[20] P. Knapp and M. Watkins, Genre, text, grammar: Technologies for teaching and assessing writing. London: UNSW Press, 2005.

[21] K. N. T. Bloor, K. Nwogu, Thematic progression in professional and popular medical texts. Berlin: Mouton de Gruyter, 1991.
[22] M. Khedri, S. F. Ebrahimi, The essence of thematic structures in the academic translated texts. Journal of Education and Practice, 3 (1) (2012) 37-43.

[23] D. P. P. Purba, Thematic progression in recount text written by the eight grade students. Doctoral dissertation, 2018.

[24] A. K. Alboghobeish, H. Sedghi, Information development in Arabic research article abstract. International Journal of English and Education, 3(1) (2014) 42-49.

[25] Q. Yang, J. A. Ramírez, R. Harman, EFL Chinese students and high stakes expository writing: A theme analysis. Colombian Applied Linguistics Journal, 9 (2007) 99-125.

[26] S. B. Merriam, Case study research in education: A qualitative approach, Berlin: Jossey-Bass, 1988.

[27] R. S. Malik, F. A. Hamied, Research methods: A guide for first time researchers. New York: Pearson, 2014.

[28] G. Forey, Aspects of theme and their role in workplace texts, Doctoral dissertation, University of Glasgow, 2002.

[29] F. Danes, Functional sentence perspective and the organization of the text. Papers on functional sentence perspective, 23 (1974) 106-128.

[30] F. Christie, Classroom discourse analysis: A functional perspective. Berlin: Bloomsbury Publishing. 2005 